\title{
ACORDES E DISSONÂNCIAS DO LETRAMENTO CIENTÍFICO PROPOSTO PELO PISA 2015
}

ANDREA MARA VIEIRA

\section{RESUMO}

A nossa proposta é investigar a existência ou não de sintonia entre o conceito acadêmico de letramento científico e aquele previsto nos documentos do Programme for International Student Assessment (PISA) e nas normas educacionais. A despeito de toda complexidade e polissemia conceitual existente em torno do conceito de alfabetização/letramento científico, desenvolvemos uma análise teórico-comparativa desse conceito na forma como é concebido pelos especialistas, em comparação com 0 conceito de letramento científico previsto na base avaliativa do PISA 2015, considerando também a previsão normatizada pelas políticas públicas educacionais. Ao final, identificamos menos acordes e, por variados motivos, mais dissonâncias, que podem servir como contributo para uma reflexão sobre a validade e relevância do PISA enquanto instrumento de avaliação, bem como sobre o tipo de aprendizagem a ser assegurada pelo nosso sistema educacional.

PALAVRAS-CHAVE LETRAMENTO CIENTÍFICO • PISA • POLÍTICAS PÚBLICAS • AVALIAÇÃO EM LARGA ESCALA. 


\section{ACORDES Y DISONANCIAS DEL LETRAMENTO CIENTÍFICO PROPUESTO POR EL PISA 2015}

RESUMEN

Nuestra propuesta es investigar la existencia o no de sintonía entre el concepto académico de letramento científico y el previsto en los documentos del Programme for International Student Assessment (PISA) y en las normas educacionales. A pesar de toda la complejidad y polisemia conceptual existentes en torno al concepto de alfabetización/letramento científico, desarrollamos un análisis teórico-comparativo de dicho concepto en la forma como es concebido por los especialistas, en comparación con el concepto de letramento científico previsto en la base evaluativa del PISA 2015, considerando también la previsión normalizada por las políticas públicas educacionales. Al final, identificamos menos acordes y, por variados motivos, más disonancias, que pueden servir como contribución para una reflexión sobre la validad y relevancia del PISA como instrumento de evaluación, así como sobre el tipo de aprendizaje que nuestro sistema educacional debe asegurar.

PALABRAS CLAVE LETRAMENTO CIENTÍFICO • PISA • POLÍTICAS PÚBLICAS • EVALUACIÓN EN GRAN ESCALA.

\section{CHORDS AND DISSONANCES OF SCIENTIFIC LITERACY PROPOSED BY PISA 2015}

ABSTRACT

Our proposal is to investigate the harmony or lack of it between the academic concept of scientific literacy and the one stated in the documents of the Program for International Student Assessment (PISA) and in educational standards. Despite all complexity and conceptual polysemy around the concept of literacy/scientific literacy, we developed a theoretical comparative analysis of this concept as designed by experts, comparing it to the concept of scientific literacy laid down on the assessment basis of the PISA 2015, considering also the projection standardized by public educational policies. Finally, we identified less chords, and, for various reasons, more dissonance, that can serve as a contribution to discuss the validity and relevance of PISA as an assessment tool, as well as on the type of learning to be ensured by our educational system.

KEYWORDS SCIENTIFIC LITERACY - PISA - PUBLIC POLICIES • LARGE-SCALE ASSESSMENT. 
1 “[...] pensamento que relaciona o que por origens diversas e múltiplas formas forma um tecido único e inseparável: complexus" (MORIN, 1991, p. 257)

\section{INTRODUÇÃO}

O letramento científico possui variados pontos de ancoragem, sendo utilizado principalmente como critério de avaliação do conhecimento do Programme for International Student Assessment (PISA), que serve como instrumento e subsídio para a consolidação e/ou mudança das políticas públicas educacionais. Os diversos matizes da alfabetização/letramento científico compõem, ou ao menos deveriam compor, um tecido complexus ${ }^{1}$ em que aspectos gnosiológicos, ontológicos, epistemológicos, pedagógicos e político-educacionais interagem, alimentam-se e retroalimentam-se.

Em que pese a nossa discordância quanto à forma, aos critérios e objetivos das avaliações, especialmente quanto às avaliações externas ou de larga escala (o que aqui não está posto em discussão), é preciso reconhecer que o PISA é uma realidade e tem o "letramento científico como ponto central da avaliação em ciências" (BRASIL, 2015, p. 36).

No entanto, para que a educação seja prioridade em relação aos resultados, é importante que haja sintonia entre os objetivos do PISA, os ensinamentos acadêmico-científicos e as políticas públicas nacionais e internacionais. 
A despeito de toda complexidade e polissemia conceitual da alfabetização/letramento científico, pretendemos investigar os acordes e as dissonâncias existentes entre o letramento previsto no domínio-chave do PISA 2015 e a alfabetização/letramento científico concebido pelos especialistas, ambos em relação às políticas públicas educacionais.

A nossa metodologia consiste em análise teórico-comparativa entre as normas que regem o PISA 2015 e as normatizações e orientações específicas do ensino de ciências, sob a luz do pensamento de especialistas em alfabetização/letramento, desenvolvido ao longo deste século. Iniciaremos com a análise do conceito de alfabetização e letramento científico sem a pretensão de uma revisão bibliográfica. Ao contrário, partiremos de recorte espacial e temporal que privilegie o debate ocorrido no Brasil ao longo do século XXI, considerando autores (brasileiros e estrangeiros que serviram de referência) que admitem a polissemia conceitual e apresentam à análise as variadas definições, regularidades e inflexões. Em seguida, apresentaremos as propostas contidas no PISA 2015, quando então estaremos aptos a identificar os possíveis acordes e dissonâncias entre o que a literatura concebe por letramento científico e o que serve de motriz para as políticas públicas, bem como os impactos e perspectivas.

\section{SOBRE OS SIGNIFICADOS E O CONCEITO DE ALFABETIZAÇÃO/LETRAMENTO CIENTÍFICO}

Muito se tem abordado e debatido, no processo de ensino-aprendizagem de ciências, o termo e o conceito de alfabetização científica e letramento científico, ${ }^{2}$ que, além dos variados sentidos, enfrentam também problemas de tradução. Segundo Cachapuz et al. (2008), o termo "literacia científica" equivale à expressão de origem norte-americana science literacy, introduzida na educação científica no ano de $1958,{ }^{3}$ surgida nos países francófonos e traduzida em Portugal, Brasil e Espanha como sinônimo de "alfabetização científica". Sasseron e Carvalho (2011) advertem que, nos países de língua portuguesa, a expressão scientific literacy vem sendo traduzida como "Letramento científico”, enquanto, nas publicações de língua espanhola

2 Embora a previsão legal contida no art. $4^{\circ}$, inc. IX da Lei de Diretrizes e Bases (LDB), que trata do dever do Estado no caso da educação básica, refira-se ao "processo de ensino-aprendizagem", tratando-o como único, essa não é a nossa única referência, posto que nos respaldamos sobretudo no pensamento de Paulo Freire, para quem o ato de ensinar-aprender constitui um único processo, dialógico e inter-relacional: "quem forma se forma e re-forma ao formar e quem é formado forma-se e forma ao ser reformado" (FREIRE, 2008, p. 23).

3 Os autores fazem referência ao artigo: HURD, P. D. Science literacy: Its meaning for American schools. Educational Leadership, 1958. Disponivel em: <http://ascd com/ASCD/pdf/journals/ed_lead/ el_195810_hurd.pdf>. Acesso em: 20 jan. 2017 . 
e francesa, aparecem as expressões alfabetización científica e alphabétisation scientifique, respectivamente. Ainda de acordo com Sasseron e Carvalho (2011), no Brasil, face ao pluralismo semântico, ambas expressões são utilizadas. As pesquisadoras citam autores como Mamede e Zimmermann (2005), Santos e Mortimer (2001), que utilizam o termo "letramento científico", e Brandi e Gurgel (2002), Auler e Delizoicov (2001), Lorenzetti e Delizoicov (2001), Chassot, (2000), que adotam o termo "alfabetização científica", havendo "também aqueles que usam a expressão "enculturação científica”, como Carvalho e Tinoco (2006) e Mortimer e Machado (1996) (SASSERON; CARVALHO, 2011, p. 60). Roberts (2007) destaca a inexistência de consenso na comunidade internacional de educação científica quanto à definição do termo scientific literacy; todavia, argumenta que o termo possui duas visões em lugar de definições, por entender que a visão é uma categoria analítica mais ampla. Com isso, denomina de Visão I aquele letramento que se restringe à perspectiva interna da ciência, voltada para o conteúdo científico, e de Visão II aquele em que os estudantes se veem como cidadãos e percebem que a ciência desempenha um papel na sociedade, sendo detentora de componentes de variadas ordens que não apenas científica.

Embora os debates sobre alfabetização/letramento científico sejam bastante ampliados, Roberts (2007), ao deslocar o olhar do campo da definição para o campo da Visão, sobretudo quando traz à cena o conceito de Visão II, auxilia-nos a entender por que o tema é bastante debatido entre os especialistas em "Ciência, Tecnologia e Sociedade" (CTS), uma vez que os objetivos propostos pela abordagem CTS extrapolam a concepção do conteúdo científico, com vistas à compreensão do desenvolvimento da ciência e da tecnologia em interação com a vida social.

Referência bibliográfica de muitos autores aqui tratados, o físico teórico Gerard Fourez (1994), no livro Alphabétisation Scientifique et Technique - Essai sur les finalités de l'enseignement des sciences, com vistas ao aprimoramento da formação escolar e científica, compara a importância da alfabetização científica ao processo de alfabetização pelo qual a sociedade passou no 
final do século XIX, defendendo que, assim como esta, aquela é também um fator de inclusão social dos cidadãos.

Áttico Chassot (2000), em seu livro Alfabetização científica - questões e desafios para a educação, vive um paradoxo, pois, ao mesmo tempo que não julga adequado o termo alfabetização, por ser ocidentalizado e desconsiderar as formas de linguagens de outras civilizações, a exemplo do ideograma, utiliza, em sua obra, alfabetização em lugar de letramento, argumentando que este não está no dicionário e tampouco possui o mesmo sentido que alfabetização.

Para esse autor, a alfabetização científica envolve também cidadania e, com isso, ele tece uma crítica às discussões teóricas no ensino de ciências que sejam afastadas da realidade do aluno. Parte de uma perspectiva construtivista da ciência, como os demais autores aqui trazidos, e, dessa forma, concebe o conhecimento científico como produção cultural. Ainda que marcado por algumas especificidades, em se tratando de um conhecimento cultural, este deve ser problematizado, posto que é também submetido aos interesses sociais e políticos e sujeito a questionamentos. A alfabetização científica, é, portanto, o "conjunto de conhecimentos que facilitariam aos homens e mulheres fazer uma leitura do mundo onde vivem" (CHASSOT, 2000, p. 19). Acrescenta Chassot (2003) que o alfabetizado científico deve ser capaz de compreender a necessidade de transformar o mundo, preferencialmente em algo melhor, propiciando aos homens e mulheres uma alfabetização científica na perspectiva da inclusão social.

No artigo "Tomada de decisão para ação social responsável no ensino de ciências", Santos e Mortimer (2001) apontam o letramento científico e tecnológico como um dos principais objetivos do currículo ciência-tecnologia-sociedade, com o argumento de que o estudante cientificamente letrado está mais apto ao exercício da cidadania e, dessa forma, capacitado para a tomada de decisões, para a solução de problemas cotidianos e para agir com responsabilidade social, pautando-se em valores éticos.

O letramento científico está para além de uma linguagem científica e tecnológica; ele significa a ciência e a sua 
linguagem considerada em inter-relação com os aspectos sociais que envolvem questões históricas, filosóficas, políticas, econômicas e institucionais, sendo o letramento apenas parte de um todo complexo maior cujas partes encontram-se interligadas; por isso, segundo os autores, é necessária uma "mudança de paradigma", ou seja, de postura dos professores de ciências

[...] no sentido de incorporar às suas aulas, discussões so-

bre temas sociais, [...] atividades de engajamento social dos alunos, por meio de ações concretas; e a discussão dos valores envolvidos. (SANTOS; MORTIMER, 2001, p. 106)

No artigo "Alfabetização científico-tecnológica para quê?", Auler e Delizoicov (2001) ressaltam a importância da alfabetização científica e tecnológica, discutindo-a segundo duas perspectivas: reducionista e ampliada. A reducionista é aquela que, por desconsiderar a existência de construções subjacentes à produção do conhecimento científico-tecnológico, seria neutra, ao passo que a perspectiva ampliada busca a compreensão das interações entre ciência-tecnologia-sociedade.

A alfabetização científico-tecnológica na visão ampliada é responsável por derrubar os mitos criados pela visão reducionista, que está próxima do ideário positivista de ciências, uma vez que, segundo os autores, aquela prioriza uma educação problematizadora e dialógica sobre a inter-relação das ciências com a sociedade, aproximando-se do referencial pedagógico freireano.

Sasseron e Carvalho (2011), adeptas da "alfabetização científica”, concebem esse termo no mesmo sentido do conceito de alfabetização concebido por Paulo Freire, qual seja, de que a alfabetização é mais que o simples domínio psicológico e mecânico de técnicas de ler e escrever; é o domínio

4 FREIRE, P. Educação como prática da liberdade. São Paulo: Paz e Terra, 1980. p. 111 dessas técnicas em termos conscientes (FREIRE, $1980^{4}$ apud SASSERON; CARVALHO, 2011). A alfabetização científica deve contribuir para que a pessoa seja capaz de organizar o pensamento de maneira lógica, de forma mais consciente e crítica em relação ao mundo.

É importante compreender a "alfabetização científica" como um processo. No artigo "Alfabetização científica, ensino 
por investigação e argumentação: relações entre ciências da natureza e escola," Sasseron (2015) nos apresenta três eixos estruturantes desse processo, que "transitam entre pontos canônicos do currículo de ciências e elementos que marcam a apropriação desses conhecimentos para ações em esferas extraescolares" (SASSERON, 2015, p. 56):

Os três eixos são: (a) a compreensão básica de termos e conceitos científicos, retratando a importância de que os conteúdos curriculares próprios das ciências sejam debatidos na perspectiva de possibilitar o entendimento conceitual; (b) a compreensão da natureza da ciência e dos fatores que influenciam sua prática, deflagrando a importância de que o fazer científico também ocupa espaço nas aulas de mais variados modos, desde as próprias estratégias didáticas adotadas, privilegiando a investigação em aula, passando pela apresentação e pela discussão de episódios da história das ciências que ilustrem as diferentes influências presentes no momento de proposição de um novo conhecimento; e (c) o entendimento das relações entre ciência, tecnologia, sociedade e ambiente, permitindo uma visão mais completa e atualizada da ciência, vislumbrando relações que impactam a produção de conhecimento e são por ela impactadas, desvelando, uma vez mais, a complexidade existente nas relações que envolvem o homem e a natureza. (SASSERON, 2015, p. 57)

Santos (2007) propõe a definição de letramento científico a partir do conceito de letramento desenvolvido pela linguista Magda Soares, para quem letramento significa um sentido ampliado da alfabetização, que seria aprender a ler e a escrever. Assim, o termo letramento refere-se ao "estado ou condição de quem não apenas sabe ler e escrever, mas cultiva e exerce práticas sociais que usam a escrita" (SOARES, $1998^{5}$ apud SANTOS, 2007). Não há uma supressão da alfabetização em favor do letramento, e tampouco este significa, 5 SOARES, M. Letramento: um tema em três gêneros. Belo Horizonte: por si, alfabetizar.

No livro Letramento: um tema em três gêneros (2010), a autora esclarece que o termo letramento surgiu no Brasil na segunda metade da década de 1980 , com o objetivo de 
distinguir-se do conceito de alfabetização, que era o aprendizado da codificação da escrita:

[...] a pessoa que aprende a ler e a escrever - que se torna alfabetizada - e que passa a fazer uso da leitura e da escrita, a envolver-se nas práticas sociais de leitura e escrita - que se torna letrada - é diferente de uma pessoa que não sabe ler e escrever - é analfabeta - ou, sabendo ler e escrever, não faz uso da leitura e da escrita - é alfabetizada mas não é letrada. (SOARES, 2010, p. 36)

Soares (2004), no artigo "Letramento e alfabetização: as muitas facetas”, promove uma espécie de revisão do seu próprio pensamento e propõe a análise da "invenção" da palavra e do conceito de letramento e simultaneamente a "desinvenção" do conceito de alfabetização, resultando no que passou a denominar de "reinvenção" da alfabetização, em que ambos os conceitos - alfabetização e letramento -, embora individualizáveis, passam a coexistir indissociavelmente:

[...] a entrada da criança (e também do adulto analfabeto) no mundo da escrita ocorre simultaneamente por esses dois processos: pela aquisição do sistema convencional de escrita - a alfabetização - e pelo desenvolvimento de habilidades de uso desse sistema em atividades de leitura e escrita, nas práticas sociais que envolvem a língua escrita o letramento. (SOARES, 2004)

Nessa esteira, a autora defende que alfabetização e letramento são processos interdependentes, uma vez que o letramento se desenvolve através de atividades no contexto das práticas sociais de leitura, em dependência da alfabetização, mas um não precede ao outro, são simultâneos, ao contrário do que preconizava a "concepção tradicional" de alfabetização, em que se acreditava na independência e autonomia dos dois processos.

Santos (2007) traça, para o letramento científico, caminho semelhante ao percorrido por Soares (2004), mas concentra tanto a alfabetização quanto o letramento no mesmo processo, tendo em vista que a compreensão dos conteúdos é indissociável da compreensão da função social da ciência. 
Acrescenta que a concepção do letramento como prática social implica a democratização da participação ativa do indivíduo na sociedade numa perspectiva de igualdade social e, para isso, é necessário o "desenvolvimento de valores vinculados a interesses coletivos, como solidariedade, fraternidade, consciência do compromisso social, reciprocidade, respeito ao próximo e generosidade" (SANTOS, 2007, p. 480) e não subordinados aos valores econômicos.

Para melhor compreensão da ciência e de seus usos através do letramento, Santos ressalta ser imprescindível o diálogo, a interdisciplinaridade de ciência-tecnologia-sociedade, onde as humanidades desempenham papel fundamental na compreensão dos conteúdos e da função social da ciência, destacando a importância dos conhecimentos de história, filosofia e sociologia da ciência (HFSC).

Ao apresentar a educação CTS como relevante para a democratização do ensino-aprendizagem de alunos da educação básica, bem como para a formação de estudantes-cidadãos mais críticos, Santos (2008), no artigo "Educação científica humanística em uma perspectiva freireana: resgatando a função do ensino de CTS," amplia a proposta do ensino de ciências em diálogo com as humanidades e propõe uma visão humanística do ensino de ciências na perspectiva educacional de Paulo Freire, destacando que o letramento científico é um dos principais objetivos do currículo CTS.

Dessa forma, há um deslocamento do olhar das ciências para o homem, no qual também está o foco do trabalho de Paulo Freire, que, a partir de sua proposta dialógica, buscava estabelecer relações de igualdade, objetivando a transformação de uma sociedade marcada pela opressão. Estendendo o pensamento freireano à ciência e tecnologia, a conclusão a que Santos chega é que ambas, cooptadas pela globalização econômica, aumentaram a diferença entre pobres e ricos: "Todo esse contexto é marcado por um processo opressivo de exploração humana" (SANTOS, 2007, p. 125); por isso, o foco é o homem, e daí surge a importância de, nos currículos, discutirem-se os valores e reflexões críticas que possibilitem desvelar a condição humana: 
Não se trata de uma educação contra o uso da tecnologia e nem uma educação para o uso, mas uma educação em que os alunos possam refletir sobre a sua condição no mundo. (SANTOS, 2007, p. 122)

Revendo os autores que tratam da alfabetização/letramento no contexto brasileiro, inferimos a clara influência de Paulo Freire, para quem não basta ler e escrever: é preciso também fazer usos sociais da leitura e da escrita. Alfabetização foi o ponto de partida do pensamento freireano e encontra-se presente em toda a sua obra, uma vez que ser alfabetizado implica livrar-se do jugo da opressão pelo conhecimento emancipador, através da formação de uma consciência crítica forjada a partir da práxis e na relação com o mundo, em que a leitura da palavra não está desvinculada da leitura do mundo, cujos objetivos são os usos políticos e sociais da leitura e da escrita.

No livro Alfabetização: leitura do mundo, leitura da palavra (FREIRE; MACEDO, 2013), a alfabetização não significa apenas decifrar e/ou decodificar as palavras; indo além, deve possibilitar uma leitura crítica do mundo e de intervenção consciente com o objetivo de transformação da realidade, uma vez que a leitura do mundo antecede a leitura da palavra, de forma que ler a palavra significa a leitura da "palavramundo", na qual se considera a vinculação entre a palavra e a linguagem.

Os autores concebem a alfabetização como importante ferramenta de transformação, sobretudo de consciência política, porque desvela o mundo e sua realidade composta por oprimidos e opressores e permeada por diferenças culturais e sociais, interesses econômicos e políticos, configurando "uma totalidade atravessada por interesses de classe" (FREIRE; MACEDO, 2013, p. 86).

Diante das muitas definições para os termos alfabetização e letramento, em que o primeiro, para alguns autores aqui citados, extrapola o mero decifrar de palavras que nomeiam o mundo, e o segundo implica saber fazer uso das palavras (uso político para alguns), ou, ainda, alfabetização/ letramento, que possuem os mesmos significados e objetivos 
independente da utilização de um ou outro termo, podemos destacar dois importantes aspectos comuns a todas as definições: a codificação e decodificação, isto é, a compreensão dos conteúdos, e também os usos da ciência, que, para além do conhecimento da linguagem científica, possibilitam a realização de leitura crítica da realidade. Analisaremos o letramento científico considerando os traços comuns a todos os termos utilizados na literatura especializada.

Vejamos como o PISA 2015 aborda e concebe o letramento científico.

\section{LETRAMENTO CIENTÍFICO PARA O PISA 2015}

O PISA é coordenado pela rede mundial de avaliação de desempenho escolar - Organização para a Cooperação e Desenvolvimento Econômico (OCDE) - e é repetido a cada três anos, a partir de 2000 , com o objetivo de melhorar as políticas e os resultados educacionais.

Se considerarmos o ranking como um reflexo da situação real da educação, em 2012, entre os 65 países participantes do PISA, o Brasil esteve no $59^{\circ}$ lugar, com 405 pontos, contra 580 pontos da China, ocupante da primeira posição.

O resumo do PISA 2015 esclarece que os documentos que embasaram a avaliação em "letramento científico" nos "ciclos anteriores (OCDE, 1999; OCDE, 2003; OCDE, 2006) haviam elaborado a concepção de letramento científico como o construto central para a avaliação em ciências" (BRASIL, 2015, p. 3). O "conhecimento científico" para o PISA dos ciclos 2000 e 2003 incorporou o conhecimento de ciência e entendimento sobre ciência. Em 2006, o conceito de "conhecimento científico" desdobrou-se em "conhecimento de ciência" e "conhecimento sobre ciência", para a compreensão e tomada de decisões. O construto central utilizado como base para os ciclos de 2006, 2009 e 2012 permanece e o PISA 2015 parece empenhar-se na ampliação e refinamento dessas ideias.

O PISA 2015 estabelece que a "construção do letramento científico é definida em termos de conjunto de competências que se espera de um indivíduo cientificamente letrado" (BRASIL, 2015, p. 4). Do indivíduo letrado cientificamente 
exigem-se três "competências específicas de domínio": a primeira é ter a capacidade de "explicar fenômenos cientificamente"; a segunda é saber "avaliar e planejar experimentos científicos"; e a terceira é saber "interpretar dados e evidências cientificamente" (BRASIL, 2015, p. 5).

Esse conjunto de competências estabelecido pelo PISA, por sua vez, exige conhecimentos de conteúdo, procedimental e epistemológico, sendo que: i) o "conhecimento de conteúdo" é necessário para explicar cientificamente os fenômenos, avaliar e planejar experimentos e interpretar dados e evidências; ii) o "conhecimento procedimental" permite reconhecer e identificar os traços que caracterizam a pesquisa científica e embasam os diversos métodos e práticas utilizadas para estabelecer o conhecimento científico; e iii) o "conhecimento epistemológico" permite uma compreensão da lógica dos conceitos e teorias para as práticas da investigação científica. Contudo, tanto as competências quanto o conhecimento são avaliados considerando os aspectos atitudinais: "interesse na ciência" e "consciência ambiental", que compõem o domínio desde 2006, e a "valorização de abordagens científicas para investigação", que foi alterada para compor a matriz de 2015. Os contextos de avaliação do PISA 2015 foram modificados na avaliação de 2006 para "pessoal, local/nacional e global". Veja a seguir a síntese do que foi dito acima:

FIGURA 1 - Matriz da Avaliação de Letramento Científico para o PISA 2015

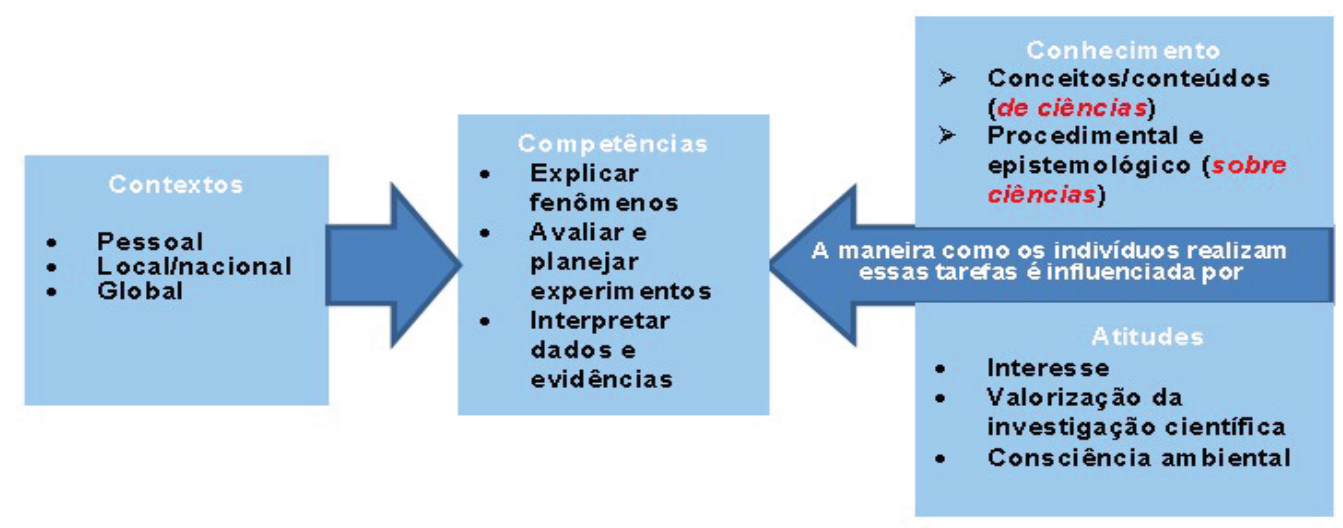


Com isso, a competência "Explicar fenômenos cientificamente" requer do estudante o conhecimento de conteúdo apropriado a uma determinada situação e também a capacidade de usá-lo para interpretar e explicar as implicações potenciais do conhecimento científico para a sociedade. Já a competência "Avaliar e planejar experimentos científicos" é importante para avaliar relatos de descobertas e investigações científicas de forma crítica. Por fim, a competência "Interpretar dados e evidências cientificamente" requer do estudante a capacidade de interpretar o significado dos dados e evidências científicas com suas próprias palavras, bem como suas implicações. E todas as competências, como dito anteriormente, exigem do aluno as três formas de conhecimento: de conteúdo, procedimental e epistemológico.

Por fim, quanto às atitudes que representam os reflexos do aprendizado e aplicações da ciência, vimos, no quadro acima, que a avaliação PISA 2015 dividiu a avaliação das atitudes dos estudantes em relação à ciência em três áreas consideradas fundamentais para a construção de letramento científico: o "interesse pela ciência e tecnologia", a "consciência ambiental" e a "valorização da investigação científica".

A primeira atitude foi escolhida por causa das relações estabelecidas com a questão pessoal, com a escolha do curso e da carreira e com a aprendizagem ao longo da vida. A segunda é importante para que os jovens estudantes compreendam e organizem suas vidas em conformidade com os princípios básicos da ecologia e meio ambiente e se preocupem com o desenvolvimento sustentável, bem como com a importância das questões ambientais para a continuidade da vida na terra e para a sobrevivência da humanidade. A escolha da terceira atitude se deu em decorrência dos resultados bem-sucedidos das abordagens científicas na geração de novos conhecimentos; através dela, os alunos podem identificar e também valorizar novas formas científicas de coleta de dados e evidências, assim como desenvolver o pensamento criativo e crítico, na medida em que enfrentam situações de vida relacionadas com a ciência e tecnologia.

Demonstrados os elementos que constituem o conceito de letramento científico adotado pelo PISA 2015, passamos 
à análise das possíveis dissonâncias e acordes quanto a alfabetização/letramento científico discutido entre pesquisadores acadêmicos e presentes nas políticas públicas educacionais.

\section{DISSONÂNCIAS DO LETRAMENTO CIENTÍFICO PROPOSTO PELO PISA 2015}

Considerando as principais bases que compõem o PISA 2015 dentre as quais, possibilitar que o indivíduo cientificamente letrado seja capaz de explicar fenômenos, avaliar e planejar experimentos e saber interpretar dados e evidências; possibilitar aos jovens estudantes adquirir atitudes no sentido de compreender e organizar suas vidas em conformidade com as questões ambientais e de sobrevivência da humanidade; capacitar os jovens para identificar e valorizar formas científicas de coleta dados e evidências; e desenvolver nos estudantes a capacidade de pensar criativa e criticamente, na medida em que enfrentam situações da vida relacionadas à ciência e tecnologia -, percebemos mais dissonâncias do que acordes, sobretudo em relação aos estudos dos especialistas.

A primeira dissonância, e talvez a mais importante, uma vez que compõe a base estrutural do PISA, é a participação do Brasil nesse nível de avaliação desenvolvida por uma organização internacional que atua em defesa das políticas econômicas de livre mercado - OCDE -, o que explicita a concepção de educação adotada pelo Brasil, voltada para o uso do conhecimento científico como forma de fomentar o mercado e desenvolver a economia.

O letramento científico defendido pelo PISA possui um viés neotecnicista, uma vez que visa a capacitar jovens que serão, ao mesmo tempo, produtores do conhecimento científico e também consumidores da informação científica, para enfrentar desafios que exigem contribuições da ciência e tecnologia a partir da perspectiva de resultados.

Na condição de organização voltada para o desenvolvimento econômico, a OCDE está naturalmente inclinada para a economia; no entanto, defendemos que preparar jovens estudantes para o emprego lucrativo não deve ser o principal objetivo da educação, a qual, ao contrário, deve preparar 
estudantes para a cidadania e participação democrática, o desenvolvimento ético, o crescimento pessoal e o bem-estar da coletividade.

Há muitas críticas de autores como Silva e Pereira (2016) e Freitas $(2011,2014)$ sobre o desvirtuamento da avaliação externa, uso e finalidade das políticas públicas, de onde se depreende a cooptação da educação, sobretudo a científica e tecnológica, pela economia, na qual a OCDE tornou-se o principal agente nas decisões políticas sobre rendimentos a serem alcançados pelos sistemas educacionais públicos dos países avaliados, tendo como principal critério o alcance da meta econômica aferida através do PISA, que se destina a "difundir uma concepção de educação voltada para os interesses econômicos” (SILVA; PEREIRA, 2016, p. 153).

Silva e Pereira, no artigo "A educação fotografada pelo PISA e difundida pela OCDE”, defendem que:

A ideologia construída em torno da sociedade do conhecimento atua como mola propulsora de uma concepção de educação [...] oriunda das determinações do capital [...] que tem como finalidade central o atendimento a um mercado de trabalho que passa a exigir novos tipos de formação escolar e de treinamento influenciados pelas novas Tecnologias de Informação e Comunicação (TIC) dominantes. (SILVA; PEREIRA, 2016, p. 143)

Acadêmicos ao redor do mundo, motivados pelo desejo de melhorar a educação, em carta dirigida ao presidente da OCDE (ANDREWS, 2014) ${ }^{6}$,registraram a sua indignação no sentido de tentar entender como essa organização se tornou o árbitro global dos meios e dos fins da educação em todo o mundo, assumindo o poder de moldar a política de educação de forma impositiva, sem debate sobre a necessidade ou as limitações dos objetivos da OCDE, desrespeitando a diversidade de tradições e culturas educacionais regionais e locais, usando critério único, estreito e tendencioso, que ao final pode vir a causar danos irreparáveis às escolas.

A crítica de Freitas (2014) é ainda mais incisiva no sentido de demonstrar que a avaliação de aprendizagem e a avaliação institucional, ambas fortalecidas pela "avaliação externa e
6 Carta enviada por acadêmicos de todo o mundo (o Brasil não possui signatário), no ano de 2014, ao Dr. Andreas Schleicher, diretor do Programa Internacional de Avaliação de Estudantes da OCDE, publicada no jornal The Guardian, na qual expressam profunda preocupação com o impacto dos testes do PISA e pedem a interrupção da próxima rodada de testes. 
as políticas de responsabilização", servem de objeto de disputa entre os "reformadores empresariais" da educação ou corporate reformers, termo forjado por Diane Ravitch (2011) para designar a "coalização entre políticos, mídia, empresários, empresas educacionais, institutos e fundações privadas e pesquisadores" (FREITAS, 2014, p. 1.089).

Nesse sentido, as avaliações atendem aqueles que compartilham da ideia de que o mercado e a forma como se organiza a iniciativa privada constituem-se como proposta mais adequada para melhorar a educação, uma vez que fortalecem o controle ideológico da estrutura educacional, adequando-a ao padrão de que o mercado necessita:

O primeiro passo foi dado na primeira onda neoliberal na qual os reformadores empresariais asseguraram o papel da avaliação externa nacional e censitária e a fortaleceram nas últimas duas décadas pela conversão do Instituto Nacional de Estudos Pedagógicos (Inep), órgão do Ministério da Educação, em uma agência nacional de avaliação. (FREITAS, 2014, p. 1.089)

A nosso ver, no caso brasileiro, em que o Estado ainda é muito presente em termos normativos e ideais, percebemos um movimento plutocrático crescente (em substituição ou talvez ao lado do oligárquico), no qual a elite empresarial tem desempenhado o papel de perpetuação da ideologia reprodutivista, neotecnicista e tecnocrática da ciência como forma de controle das massas a serviço dos interesses de uma pequena elite econômica, cujo objetivo final é fomentar a economia em seu favor, mantendo o conhecimento científico sob controle de poucos.

Mas, além da finalidade econômica do PISA, é importante destacar a importância de um elemento constitutivo comum ao PISA e à alfabetização/letramento científico, o “capital humano". Embora a Organização das Nações Unidas (ONU) utilize o conceito de capital humano para se referir àquele desenvolvido com base na educação, saúde e qualidade de vida, refletindo o Índice de Desenvolvimento Humano (IDH) e o Relatório das Nações Unidas sobre o Desenvolvimento Humano de 1996 (PROGRAMA DAS NAÇÖES UNIDAS 
PARA O DESENVOLVIMENTO, 1996), é relevante destacar a "importância da capacitação de recursos humanos e atendimento às necessidades sociais básicas como trampolim para o crescimento econômico sustentado" (CHOMSKY, 2002, p. 17). Chomsky nos adverte sobre os riscos das doutrinas neoliberais que debilitam a educação e a saúde, contribuindo para o aumento da desigualdade social.

Para os teóricos da Escola de Chicago, o capital humano, que foi uma de suas expressões mais marcantes, refere-se a um conjunto de habilidades e capacitações humanas que adquire valor de mercado, apresentando-se como forma de capital.

Theodore W. Schultz, importante representante da Escola de Chicago, em conferência proferida em 1959, na Universidade de Chicago, e publicada posteriormente, intitulada "Investimento no homem: a visão de um econonmista", sugeriu a hipótese de que as pessoas são uma forma de riqueza e, por isso, devem integrar o cálculo econômico, uma vez que os habitantes são parte importante da riqueza das nações. López-Ruiz destaca do pensamento de Schultz que:

[...] estamos fortemente inibidos de olhar para os homens como um investimento, exceto na escravidão, e isso nós abominamos. Tampouco é bom para nosso entendimento ver o homem olhar-se a si mesmo como um investimento, isso também pode resultar-nos degradante. Nossas instituições políticas e legais têm sido moldadas para manter o homem livre da escravidão. [...] É por isso que é compreensível [entender] por que o estudo do homem, tratando-se a si mesmo como se fosse riqueza, vai contra valores profundamente arraigados. [...] Nada menos que J. S. Mill insistia que os habitantes de uma nação não devem ser vistos como riqueza porque a riqueza existe só por e para os habitantes. [...] Mas certamente Mill estava equivocado, porque não há nada no conceito de riqueza humana que implique que ela pode não existir totalmente em benefício dos habitantes. [...] $\bigcirc$ que é difícil de explicar, no entanto, é que os economistas modernos hajam negligenciado por tanto tempo o investimento no homem (SCHULTZ, 1959, p. 1107 apud LÓPEZ-RUIZ, 2009, p. 218).

7 SCHULTZ, T.W. Investment in man: an economist view. The Social Service Review, Chicago, v. XXXIII, n. 2, p. 109-117, jun. 1959. 
A nova perspectiva inaugurada com a Escola de Chicago passa a conceber a educação como consumo e investimento, pois, uma vez consumida, volta ao mercado como investimento, como capital humano. O "Consenso de Washington", responsável pelo ajustamento macroeconômico dos países em desenvolvimento, que teve relevante participação no fomento da educação no contexto da produtividade e do crescimento econômico, surge como um exemplo da incorporação da teoria do capital humano na política econômica.

Nesse sentido, é fundada a tônica dada pela Escola de Chicago de como se produz e se acumula o "capital humano", ou seja, com a reintrodução do trabalho em uma análise econômica da relação custo/benefício. Foucault (2008, p. 308), ao analisar a Escola de Chicago, repete o que Karl Marx já havia dito e adverte que o trabalho e o homem passam a comportar a um só tempo capital e renda.

Ao estudar a teoria da Escola de Chicago em interface com a educação, concluímos que a primeira atribui importância à segunda, mas a trata como investimento, indo ao encontro do identificado por Silva e Pereira quando da análise dos índices do PISA utilizados pela OCDE. O mesmo ocorre em relação à avaliação do letramento, dentre cujos objetivos está o desenvolvimento de habilidades com finalidades econômicas, enquanto o objetivo educacional do "letramento científico" defendido pelos autores trazidos no início deste texto é o de empoderamento como cidadão, cujo foco é o desenvolvimento das potencialidades quanto à compreensão da ciência com vistas à emancipação e o poder de decisão, aliado aos valores éticos.

A adesão do Brasil aos índices de avaliação externa como o PISA mostra o deslocamento de finalidade da educação da formação do sujeito para a educação como investimento e produto de mercado - e denuncia o tipo de educação que pretendemos alcançar, lembrando que, nos dois casos, a alfabetização/letramento científico mostra-se essencial.

Essa reflexão converge para demonstrar que os objetivos do PISA são dissonantes dos objetivos da educação científica defendida pelos autores que abordam a alfabetização/ letramento científico, uma vez que, para estes, a meta final 
da educação é a emancipação do indivíduo a partir do desenvolvimento de uma consciência crítica da ciência em sua relação com o mundo, bem como a preocupação com os usos que se faz dela.

A segunda dissonância também compõe a base estrutural do PISA, posto que, embora este constitua como competência a capacidade de interpretação e de atitudes que permitam aos jovens, por exemplo, compreender e organizar suas vidas em conformidade com as questões ambientais e de sobrevivência da humanidade, em poucos momentos, $o$ PISA 2015 refere-se à compreensão de contextos históricos e, em momento algum, ressalta a importância de se conhecer mais sobre as humanidades em geral e as relações da ciência com a filosofia, sociologia e a própria história, em total descompasso com as políticas públicas educacionais atuais vide Organização das Nações Unidas para a Educação, a Ciência e a Cultura (Unesco) e Orientações Curriculares (BRASIL, 2010). A meta econômica aniquila a concepção das ciências a partir dos aspectos históricos, sociais e filosóficos voltados às questões gnosiológicas, ontológicas e epistemológicas nas quais a validade do conhecimento em função do sujeito cognoscente e o campo da pesquisa ocupam importante papel, assim como os aspectos de historicidade e prática social.

Aliás, é sintomático que a preocupação com a dimensão histórica, filosófica e social da ciência não se encontre presente na base avaliativa do PISA, especialmente porque ele sequer considera o "letramento em humanidades" como sendo um "domínio-chave", tal qual o "letramento em leitura, matemática e ciências". Questionamo-nos como pode um iletrado em humanidades despertar-se para a análise criativa e crítica da ciência. Como pode compreender a sua atitude perante o mundo incluindo a natureza, no sentido de harmonizá-la conscientemente com a ciência e a tecnologia? São muitos questionamentos para uma mesma resposta: é preciso que os cientistas e estudantes sejam letrados em humanidades para que o tecnocrata dê lugar ao homem, compreendendo a si e à ciência em toda a sua complexidade. Não é interesse do PISA avaliar as humanidades, uma vez que estas não são aptas a se transformar em produto de 
mercado, mas, ao contrário, servem como instrumento de crítica contra as próprias bases avaliativas.

O letramento científico constitui aspecto relevante na formação do cidadão, que, ao lado do letramento em linguagens e matemática, além do letramento em política e humanidades - os dois últimos não contemplados pelo sistema avaliativo do PISA -, formariam a educação universal, aproximando-se da Paideia grega de Platão ou da Bildung alemã.

Como vimos, a alfabetização/letramento defendida por autores como Roberts (2007), Santos (2007) e Sasseron (2015) propõem uma educação para além de aprender o conteúdo e, sim, que os estudantes se percebam enquanto cidadãos e não apenas como detentores do saber científico, o que os conduz à percepção do papel da ciência na e para a sociedade. A ênfase na inter-relação entre ciência-tecnologia-sociedade é uma proposta clara de diálogo das ciências com as humanidades, ou seja, história, filosofia e sociologia, na qual estas desempenham importante papel não só na compreensão dos conteúdos, mas também na democratização do ensino de ciências, no desenvolvimento do olhar crítico sobre a ciência, no desenvolvimento de posturas éticas e de habilitação para os usos sociais da ciência, tomada de decisão e exercício da cidadania.

Nesse sentido, a avaliação da educação científica constitui um simulacro por duas razões: a primeira, porque a previsão do PISA quanto à compreensão de aspectos epistemológicos da ciência se dá a partir da lógica dos conceitos e teorias, ou seja, de uma perspectiva internalista da ciência, contribuindo para uma ciência estandardizada, reprodutivista e acrítica, distante das definições de alfabetização/letramento discutidas na primeira parte do texto; e a segunda, porque o que está em pauta não é a qualidade da educação com base nas diretrizes e princípios educacionais, mas o foco no resultado econômico.

A terceira dissonância que detectamos no PISA 2015 diz respeito à falta de observância e alinhamento com a legislação que normatiza o ensino de ciências. O PISA 2015 não está alinhado ao que dispõem as bases estipuladas pela Unesco, as Orientações Curriculares e a Orientação Educacional, 
ainda que expressamente não tratem da alfabetização/letramento científico.

A Lei de Diretrizes e Bases (LDB), Lei n. 9.394/96 (BRASIL, 1996), um dos principais instrumentos do ordenamento jurídico na área de educação, prevê, entre os seus fundamentos, a educação como dever da família e do Estado inspirada nos princípios de liberdade e nos ideais de solidariedade humana, visando ao pleno desenvolvimento do educando, seu preparo para o exercício da cidadania e sua qualificação para o trabalho.

Com as alterações trazidas pela Lei n. 11.741/08, a LDB institucionalizou e integrou as ações da educação profissional e tecnológica às diretrizes e bases da educação nacional, mas não de forma dual, como se a educação e a educação para o trabalho pertencessem a categorias distintas. A lei em sua totalidade, sobretudo os artigos que tratam dos princípios e finalidades, aplica-se aos diferentes níveis e modalidades de educação, às dimensões do trabalho, da ciência e da tecnologia (art. 39). A educação e educação para o trabalho são tratadas de forma integrada.

O capítulo que dispõe sobre a educação profissional técnica e tecnológica enfatiza: o "aprimoramento do educando como pessoa humana, incluindo a formação ética e o desenvolvimento da autonomia intelectual e do pensamento crítico" (art. 35, III); e a compreensão dos fundamentos científico-tecnológicos dos processos produtivos, relacionando a teoria com a prática (art. 35, IV).

O Plano Nacional de Educação (PNE), Lei n. 13.005/14 (BRASIL, 2014) tem como diretrizes a formação para o trabalho e para a cidadania com ênfase nos valores éticos, a promoção dos princípios de respeito aos direitos humanos, bem como a superação das desigualdades educacionais com ênfase na promoção da cidadania e na erradicação de todas as formas de discriminação.

As Orientações Curriculares para o Ensino Médio - Ciências da Natureza, Matemática e suas Tecnologias (BRASIL, 2006) dispõem que a escola, ao definir seu projeto pedagógico, deve propiciar condições para que o estudante, além dos fundamentos básicos da investigação científica, reconheça a 
[...] ciência como uma atividade humana em constante transformação, fruto da conjunção de fatores históricos, sociais, políticos, econômicos, culturais, religiosos e tecnológicos. (BRASIL, 2006, p. 64)

Essa Orientação Curricular enfatiza a viabilidade do uso da "história da ciência" como forma de tornar mais interessante seu aprendizado, posto que, ao aproximar os "aspectos científicos dos acontecimentos históricos, possibilita a visão da ciência como uma construção humana” (BRASIL, 2006, p. 64), assim como da "filosofia da ciência", que teria maior relevância para o professor ao construir a sua concepção de ciência, o que acabaria por se refletir na sua abordagem em sala de aula (BRASIL, 2006, p. 65).

As Orientações educacionais complementares aos Parâmetros Curriculares Nacionais - Ciências da Natureza, Matemática e suas Tecnologias preveem que a

[...] contextualização no ensino de ciências abarca competências de inserção da ciência e de suas tecnologias em um processo histórico, social e cultural e o reconhecimento e discussão de aspectos práticos e éticos da ciência no mundo contemporâneo. (BRASIL, 2010, p. 3)

A Unesco, no documento A Ciência para o Século XXI - uma nova visão e uma base de ação, propõe que devem constar dos currículos abordagens acerca da "ética da ciência, bem como formação em história e filosofia da ciência, tratando também de seu impacto cultural" (ORGANIZAÇÃO DAS NAÇÕES UNIDAS PARA A EDUCAÇÃO, A CIÊNCIA E A CULTURA UNESCO, 2005, p. 39).

Os instrumentos normativos aqui citados convergem para os debates dos teóricos da alfabetização/letramento científico, posto que também enfatizam a formação para a cidadania, permitindo uma ativa participação do sujeito na sociedade a partir de uma formação integral.

A alfabetização/letramento científico como um critério avaliativo do PISA que afere a capacidade de compreensão e utilização da informação científica deveria estar em sintonia com a legislação nacional sobre educação científica e 
também com o que vem sendo discutido e pesquisado entre os acadêmicos nacionais e internacionais.

A dissonância entre o conhecimento que se pretende aferir dos alunos letrados cientificamente e o que as políticas públicas educacionais (ainda que teoricamente) propõem e esperam da educação científica é profunda. Os requisitos para o letramento científico na perspectiva do PISA encontram-se muito aquém das propostas educacionais de formação para a educação em ciências, não bastando para estas que os alunos sejam capazes de compreender e organizar suas vidas em conformidade com as questões ambientais e de sobrevivência da humanidade: é preciso o aprimoramento do educando como pessoa humana, incluindo a formação ética e o desenvolvimento da autonomia intelectual e do pensamento crítico, visando ao pleno desenvolvimento do educando, seu preparo para o exercício da cidadania, bem como para a promoção dos princípios de respeito aos direitos humanos. Além dos fundamentos básicos da investigação científica, o aluno precisa reconhecer a ciência como uma atividade humana em movimento e em transformação e que esta é fruto da conjunção de fatores históricos, sociais, políticos, econômicos, culturais e tecnológicos.

A quarta dissonância é representada pelo gap entre o conceito de alfabetização/letramento científico desenvolvido por diversos autores neste início de século e o conceito de letramento científico defendido pelo PISA 2015, que destoa dos objetivos voltados para a valorização da educação e formação do cidadão na compreensão da ciência, da tecnologia, do mundo e da natureza em sua complexidade, de forma a desenvolver o senso crítico e prepará-lo para a tomada de decisões com responsabilidade social.

Percebemos que essa dissonância está intrinsecamente relacionada à formação de professores na área de ciências da natureza, cujos currículos, em sua maioria, não possibilitam disciplinas ou debates acerca da compreensão da Natureza da Ciência, de suas concepções ao longo do tempo e de suas variadas dimensões, o que impacta negativamente no ensino de ciências. Os professores ainda são formados a partir de uma visão dogmática da ciência, embora inúmeras 
sejam as transformações do conceito de ciências e de suas abordagens, trazidas pelas orientações construtivistas da ciência por autores como Thomas Kuhn, Bruno Latour e Paul Feyerabend, para citar alguns.

Para reduzir o gap entre a alfabetização/letramento científico abordado na literatura especializada e o letramento científico proposto pelo PISA, e com isso garantir uma formação integral aos estudantes, faz-se necessário o investimento na formação de professores, proporcionando-lhes uma compreensão acerca da Natureza da Ciência em sua inteireza, com acesso às concepções de ciência em sua historicidade, $o$ que representaria uma reestruturação no ensino de ciências e na educação científica, com reflexos na alfabetização/letramento científico.

Assim, as dissonâncias apresentadas constituem a base da nossa crítica no sentido de dizer que, se defendemos um ensino de ciências menos opressor e reprodutivista e mais crítico e democrático, dizemos com isso que é preciso que a educação esteja livre do jugo do mercado, posto que incompatível com os objetivos econômicos. Não podemos nortear a nossa educação por critérios avaliativos que objetivem prioritariamente o desenvolvimento econômico em lugar do desenvolvimento do ser humano, do conhecimento dualista em lugar da formação integral, dos valores financeiros em substituição aos valores éticos, sociais e democráticos. Por isso, a nosso ver, a avaliação do PISA está maculada em sua base, em seu nascedouro, o que compromete o objetivo primeiro das avaliações, que são os aspectos educacionais. Como tal, em que pesem as políticas neoliberais e globalizadas de mercado, as avaliações devem atender aos interesses do conhecimento e ensino-aprendizagem e não às imposições mercadológicas.

\section{ACORDES DO LETRAMENTO CIENTÍFICO PROPOSTO PELO PISA 2015}

Podemos classificar como sendo um acorde, tanto em termos de políticas públicas educacionais quanto em termos do que se tem estudado sobre a educação em ciências, a própria 
valorização da alfabetização/letramento científico, não apenas no sentido do educando assimilar o conteúdo científico e explicar os fenômenos, mas também de compreendê-los e ter a capacidade de desenvolver as próprias habilidades na organização de sua vida, em conformidade com as "questões ambientais para a continuidade da vida na Terra e para a sobrevivência da humanidade" (BRASIL, 2015, p. 22), esclarecendo que o que distancia as duas propostas de letramento são os objetivos finais.

Percebemos também um foco maior na preservação ambiental e desenvolvimento sustentável, muito embora o PISA não esclareça que é salutar a interdisciplinaridade, a dialogia e a problematização das questões para que os educandos, futuros cientistas e professores não perpetuem a tecnocracia e os três mitos criticados por Auler e Delizoicov, quais sejam: a superioridade do modelo de decisões tecnocráticas, a perspectiva salvacionista da ciência e tecnologia e o determinismo tecnológico.

Sendo assim, vimos que as dissonâncias são muito maiores e o diagnóstico que fazemos do PISA 2015 é de que ele está defasado em relação às políticas públicas e aos estudos acadêmicos, o que talvez seja um reflexo do que é possível avaliar a partir da educação e letramento científicos atuais, que estão muito próximos, por um lado, dos ideais positivistas do século XIX, em que se defendia uma ciência neutra, bastando ao aluno conhecer e dominar os conceitos sem refletir sobre eles, e, por outro, dos ideais neoliberais e das políticas de mercado.

\section{CONSIDERAÇÕES: IMPACTOS E PERSPECTIVAS PARA 0 LETRAMENTO CIENTÍFICO}

Os objetivos econômicos que compõem a base estrutural do PISA mostram-se suficientes para eliminar do sistema de avaliação educacional esse tipo de avaliação externa, ou seja, avaliação desenvolvida por organização internacional que atua em defesa de políticas econômicas de livre mercado (nesse caso OCDE), na qual o conhecimento científico é concebido, prioritariamente, como forma de fomento do mercado e 
desenvolvimento da economia, servindo de referencial apenas para políticas públicas econômicas de governo e não para o avanço das políticas públicas educacionais voltadas para o conhecimento científico que tenha como objetivo a formação do sujeito e do cidadão. O ranqueamento da educação (leva muitos governos a uma competição internacional por pontuações mais altas) é pernicioso porque representa a pior face mercadológica, que é a da competição com vistas ao resultado/produto, e o PISA em particular alimenta a educação hegemônica, o imperialismo educacional e a manutenção e crescimento da desigualdade social e educacional. O maior problema do PISA é o próprio PISA, posto que as suas avaliações, que desconsideram as diferenças sociais e educacionais cujos resultados possuem objetivos meramente econômicos, mostram-se inúteis para fins educacionais.

No entanto, se a escolha se der no sentido de permanecer com o PISA como sistema de avaliação, isso nos conduz a uma pergunta: como equacionar a questão, já que a proposta do PISA para alfabetização/letramento científico possui finalidades tão díspares daquelas que compõem os objetivos educacionais presentes na LDB, nos Parâmetros Curriculares, nas Orientações Educacionais, nas orientações da Unesco, bem como nas obras dos autores aqui debatidos? Primeiramente, é fundamental refletir sobre qual tipo de educação queremos para o nosso país, ou seja, sobre qual o direito à aprendizagem que o aluno deve ter assegurado. Definir esse parâmetro é essencial para que as escolas desenvolvam estratégias para promover educação de qualidade, e isso envolve o tipo de avaliação a ser considerada para o avanço das políticas educacionais. Em seguida, é importante que escola e o professor façam uma autoavaliação e articulem avaliação de aprendizagem (interna) e avaliação institucional com avaliação de desempenho (externa), sem que esta prevaleça sobre as demais, sob pena de reforçar não somente o colonialismo econômico, mas também o educacional.

Nesse sentido, conviver com o PISA em seu formato atual e pretender uma educação com foco no conhecimento representa a existência de conflito de interesses, e, a nosso ver, a prioridade é o conhecimento e a formação, o que nos 
conduz a minimizar (pra não dizer desprezar) a avaliação do PISA e priorizar a reformulação do ensino-aprendizagem de ciências na educação básica. Antes, porém, é preciso reestruturar a formação de professores cujos conhecimentos devem permitir uma compreensão da Natureza da Ciência de maneira ampliada, considerando as suas variadas concepções e dimensões. Compreender o processo histórico e social da ciência, o seu desenvolvimento e o papel que ela desempenha na e para a sociedade contribuem para a formação de um tipo de consciência científica por parte dos professores, permitindo-lhes desenvolver com criatividade novas formas de tornar a ciência mais compreensível para os alunos da educação básica.

Deslocar o olhar da avaliação para o conhecimento significa dizer que, mais do que resultados, precisamos de escolas e professores que se preocupem com a alfabetização/ letramento científico voltado para a formação de consciência crítica que ensine a duvidar das certezas em lugar de somente reafirmá-las. Por isso a relevância do educador crítico que contribui para que os envolvidos possam se apropriar do conhecimento e utilizá-lo como instrumento de transformação social, como defende Freire.

Ressaltamos a importância da alfabetização/letramento científico na forma como defendido por Chassot (2000, 2003), Auler e Delizoicov (2001), Santos (2007), Roberts (2007), Cachapuz et al. (2008) e Sasseron (2015), por exemplo. Entretanto, o letramento científico somente se consolidará de maneira plena com uma formação educacional que extrapole os conceitos científicos de forma a envolver aspectos inter-relacionais com a sociedade num profícuo diálogo com as humanidades, ou seja, com a história, filosofia, sociologia, política e áreas subjacentes, proporcionando uma compreensão sobre a ciência, o seu papel e desenvolvimento. Os critérios avaliativos do PISA não atendem à educação universal prevista nas políticas educacionais e nos debates acadêmicos aqui trazidos.

As políticas educacionais brasileiras já reconheceram a necessidade de uma aproximação entre as hard sciences e as humanidades; todavia, estas destoam da realidade da sala de 
aula, que se mantém no círculo reprodutivista que insiste em perpetuar a visão dogmática da ciência defendida no século XIX e até hoje presente, inclusive nas universidades, cujo "estatuto científico forte" não permite a interdisciplinaridade e a problematização das ciências, formando professores que, em pleno século XXI, não obstante a legislação, passarão, aos seus futuros alunos da educação básica ou do ensino superior, a visão positivista que há muito tentamos superar.

O sistema de avaliação externa, como o caso do PISA, aponta para avaliação global, cujo impacto dos resultados nos planos e práticas pedagógicas tende a conflitar com as avaliações internas de aprendizagem, pois despreza o ensino-aprendizagem e a realidade nacional e local da escola, do aluno e do professor, tendo como objetivo apenas o desenvolvimento de conhecimentos que promovam o Brasil no plano econômico. A avaliação externa somente surtirá bons resultados se passar a integrar o processo de transformação do ensino-aprendizagem; do contrário, somente contribuirá para a ampliação do fosso educacional entre ricos e pobres, acentuando ainda mais a desigualdade social.

Avaliar a educação significa dialogar com os próprios sujeitos, dando assento à mesa não somente a uma instituição preocupada com o desenvolvimento econômico, mas também aos diretamente interessados, alunos e professores, pais, gestores e estudiosos da área das ciências humanas, de maneira que possam discutir a educação e a avaliação nos níveis local, nacional e internacional, visando ao conhecimento, à formação, à saúde, ao desenvolvimento humano, ao bem-estar, à felicidade, renovando a vontade de professores e alunos de ensinar-aprender.

\section{REFERÊNCIAS}

ANDREWS, P. et al. OECD and PISA tests are damaging education worldwide academics. The Guardian, Reino Unido-UK, 6 maio 2014. Disponível em: <https://www.theguardian.com/education/2014/may/06/oecd-pisa-testsdamaging-education-academics>. Acesso em: 20 jan. 2017.

AULER, D.; DELIZOICOV, D. Alfabetização científico-tecnológica para quê? Ensaio: Pesquisa em Educação em Ciências, v. 3, n. 1, p. 105-115, jun. 2001. 
BRANDI, A. T. E.; GURGEL, C. M. A. A alfabetização científica e o processo de ler e escrever em séries iniciais: emergências de um estudo de investigação. Ação, Ciência \& Educação, v. 8, n. 1, p. 113-125, 2002.

BRASIL. Lei de Diretrizes e Bases da Educação Nacional/LDB. Lei 9394/96. Brasília, DF: Congresso Nacional, 1996.

BRASIL. Ministério da Educação. Orientações curriculares para o ensino médio: ciências da natureza, matemática e suas tecnologias. Brasília, DF, 2006. Disponível em: <http://portal.mec.gov.br/seb/arquivos/pdf/book_ volume_02_internet.pdf $>$. Acesso em: 6 set. 2015.

BRASIL. Ministério da Educação. Orientações educacionais complementares aos parâmetros curriculares nacionais: ciências da natureza, matemática e suas tecnologias. Brasília, DF, 2010, p. 31. Disponível em: <http://portal.mec. gov.br/seb/arquivos/pdf/CienciasNatureza.pdf > . Acesso em: 6 set. 2015.

BRASIL. Ministério da Educação. Plano Nacional de Educação.

Lei n. 13.005/14. Brasília, DF: Congresso Nacional, 2014. Disponível em: $<$ http://www2.planalto.gov.br/>. Acesso em: 29 maio 2016.

BRASIL. Instituto Nacional de Estudos e Pesquisas Educacionais Anísio Teixeira. OCDE PISA 2015. Programa Internacional de Avaliação de Estudantes Matriz de Avaliação de Ciências. 2015. p. 12. Disponível em: <http://download.inep.gov.br/acoes_internacionais/pisa/marcos_ referenciais/2015/matriz_de_ciencias_PISA_2015.pdf>. Acesso em: 1 jul. 2016.

CACHAPUZ, A. et al. Do estado da arte da pesquisa em educação em ciências: linhas de pesquisa e o caso "ciência-tecnologia-sociedade". Alexandria: Revista de Educação em Ciência e Tecnologia, Florianópolis, v. 1, n. 1, p. 27-49, 2008.

CARVALHO, A. M. P.; TINOCO, S. C. O ensino de Ciências como 'enculturação'. In: CATANI, D. B.; VICENTINI, P. P. (Org.). Formação e autoformação: saberes e práticas nas experiências dos professores. São Paulo: Escrituras, 2006.

CHASSOT, A. Alfabetização científica: questões e desafios para a educação. Ijuí: Editora da Unijuí, 2000.

CHASSOT, A. Alfabetização científica: uma possibilidade para a inclusão social. Revista Brasileira de Educação, Rio de Janeiro, n. 22, p. 89-100, jan./abr. 2003.

CHOMSKY, N. O lucro ou as pessoas?. Tradução de Pedro Jorgesen Jr. Rio de Janeiro: Bertrand Brasil, 2002.

FOUCAULT, M. Nascimento da biopolítica. São Paulo: Martins Fontes, 2008.

FOUREZ, G. Alphabétisation scientifique et technique: essai sur les finalités de l'enseignement des sciences. Bruxelas: DeBoeck-Wesmael, 1994.

FOUREZ, G. Science teaching and the STL movement: a socio-historical view. In: JENKINS, Edgar (Ed.). Innovations in science and technology education. Paris: Unesco, 1997. v. VI. 
FREIRE, P. Pedagogia da autonomia: saberes necessários à prática educativa. Rio de Janeiro: Paz e Terra, 2008.

FREIRE, P. Educação como prática da liberdade. 14. ed. Rio de Janeiro: Paz e Terra, 2011.

FREIRE, P.; MACEDO, D. Alfabetização: leitura do mundo, leitura da palavra.

6. ed. Tradução de Lólio Lourenço de Oliveira. Rio de Janeiro: Paz e Terra, 2013.

FREITAS, L. C. Responsabilização, meritocracia e privatização: conseguiremos escapar ao neotecnicismo? In: SEMINÁRIO DE EDUCAÇÃO BRASILEIRA, 3.; SIMPÓSIO PNE: DIRETRIZES PARA AVALIAÇÃO E REGULAÇÃO DA EDUCAÇÃO NACIONAL, 2011, Campinas. Anais... Campinas, SP: Centro de Estudos Educação e Sociedade, 2011.

FREITAS, L. C. Os reformadores empresariais da educação. Educação e Sociedade, Campinas, SP, v. 35, n. 129, p. 1085-1114, out./dez. 2014.

HURD, P. D. Scientific literacy: new minds for a changing world. Science Education, Hoboken, v. 82, n. 3, p. 407-416, 1998.

LÓPEZ-RUIZ, O. J. O consumo como investimento: a teoria do capital humano e o capital humano como ethos. Mediações: Revista de Ciências Sociais, Londrina, v. 14, n. 2, p. 217-230, jul./dez. 2009.

LORENZETTI, L.; DELIZOICOV, D. Alfabetização científica no contexto das séries iniciais. Ensaio: Pesquisa em Educação em Ciências, v. 3, n. 1, p. 37-50, 2001.

MAMEDE, M.; ZIMMERMANN. E. Letramento científico e CTS na formação de professores para o ensino de Ciências. Enseñanza de las Ciencias, Barcelona, Número Extra, 2005. VII Congreso.

MORIN, Edgar. Meus demônios. Tradução de Leneide Duarte e Clarisse Meireles. 4. ed. Rio de Janeiro: Bertrand Russel, 2003.

MORTIMER, E. F.; MACHADO, A. H. A linguagem em uma aula de Ciências. Presença Pedagógica, Belo Horizonte, v. 2, n. 11, p. 49-57, 1996.

ORGANIZAÇÃO DAS NAÇÕES UNIDAS PARA A EDUCAÇÃO, A CIÊNCIA E A CULTURA. A Ciência para o Século XXI: uma nova visão e uma base de ação. Budapeste; Santo Domingo; Brasília, DF: Unesco, 2005. Disponível em: <http://www.dominiopublico.gov.br/download/texto/ue000207.pdf.> Acesso em: 10 jul. 2015.

ORGANIZAÇÃO PARA A COOPERAÇÃO E DESENVOLVIMENTO ECONÔMICO. Classifying educational programmes: Manual for ISCED-97 implementation in OECD countries. Paris: OECD, 1999.

ORGANIZAÇÃO PARA A COOPERAÇÃO E DESENVOLVIMENTO ECONÔMICO. Measuring student knowledge and skills: The PISA 2000 assessment of reading, mathematical and scientific literacy. Paris: OECD, 2000.

ORGANIZAÇÃO PARA A COOPERAÇÃO E DESENVOLVIMENTO

ECONÔMICO. The PISA 2003 Assessment framework: Mathematics, reading, science and problem solving knowledge and skills. Paris: OECD, 2003. 
ORGANIZAÇÃO PARA A COOPERAÇÃO E DESENVOLVIMENTO

ECONÔMICO. PISA 2015: programa Internacional de Avaliação de

Estudantes. Matriz de Avaliação de Ciências. Tradução de Lenice Medeiros.

Brasília, DF: OECD; Inep, 2015. Resumo do Documento: PISA 2015 Science

Framework (2013).

PROGRAMA DAS NAÇÕES UNIDAS PARA O DESENVOLVIMENTO. Relatório do Desenvolvimento Humano Brasil 1996. Brasília, DF: Pnud, 1996. 186 p.

Disponível em: <http://www.br.undp.org/content/brazil/pt/home/library/ rdhs-brasil/relatorio-do-desenvolvimento-humano-200014.html>. Acesso em: 2 jun. 2016.

ROBERTS, D. A. Scientifc literacy/science literacy. In: ABELL, S. K.;

LEDERMAN, N. G. (Ed.). Handbook of research on science education. Londres:

Lawrence Erbaum Associates, 2007. p. 729-780.

SANTOS, W. L. P. Educação científica na perspectiva de letramento como prática social: funções, princípios e desafios. Revista Brasileira de Educação, Rio de Janeiro, v. 12, n. 36, p. 474-492, set./dez. 2007.

SANTOS, W. L. P. Educação científica humanística em uma perspectiva freireana: resgatando a função do ensino de CTS. Alexandria: Revista de Educação em Ciência e Tecnologia, Florianópolis, v. 1, n. 1, p. 109-131, mar. 2008.

SANTOS, W. L. P.; MORTIMER, E. F. Tomada de decisão para ação social responsável no ensino de ciências. Ciência \& Educação, Bauru, SP, v. 7, n. 1, p. 95-111, 2001.

SASSERON, L. H. Alfabetização científica, ensino por investigação e argumentação: relações entre ciências da natureza e escola. Ensaio: Pesquisa em Educação em Ciências, Belo Horizonte, v. 17, número especial, p. 49-67, nov. 2015.

SASSERON, L. H.; CARVALHO, A. M. P. de. Alfabetização científica: uma revisão bibliográfica. Revista de Investigações em Ensino de Ciências, Porto Alegre, v. 16, n. 1, p. 59-77, mar. 2011.

SCHULTZ, T. W. O capital humano: investimento em educação e pesquisa. Rio de Janeiro: Zahar, 1973.

SILVA, M. A.; PEREIRA, R. S. A educação fotografada pelo PISA e difundida pela OCDE. In: CUNHA, C.; SOUSA, J. V. de; SILVA, M. A. (Org.). Internacionalização da educação: discursos, práticas e reflexos sobre as políticas educativas. Belo Horizonte: Fino Traço, 2016.

SOARES, M. Letramento e alfabetização: as muitas facetas. Revista Brasileira de Educação, Rio de Janeiro, n. 25, p. 5-17, jan./abr. 2004.

SOARES, M. Letramento: um tema em três gêneros. 4. ed. Belo Horizonte: Autêntica, 2010.

SUISSO, C.; GALIETA, T. Relações entre leitura, escrita e alfabetização/ letramento científico: um levantamento bibliográfico em periódicos nacionais da área de ensino de ciências. Ciência \& Educação, Bauru, SP, v. 21, n. 4, p. 991-1009, 2015. 
ANDREA MARA VIEIRA

Doutoranda em Educação pela Universidade de Brasília (UnB), Brasília, Distrito Federal, Brasil

andreamara.vieira@gmail.com

http://orcid.org/0000000291556949 
